\title{
Emotional Intelligence as an Important Asset for HR in Organizations: Leaders and Employees
}

\author{
https://doi.org/10.3991/ijac.v12i1.9637 \\ Athanasios Drigas $\left({ }^{\bowtie}\right)$ \\ Net Media Lab, Institute of Informatics \& Telecommunications, National Centre for Scientific \\ Research "Demokritos," Greece \\ dr@iit.demokritos.gr \\ Chara Papoutsi \\ Net Media Lab, Institute of Informatics \& Telecommunications, National Centre for Scientific \\ Research "Demokritos," Greece
}

\begin{abstract}
Emotional intelligence (EI) is related to emotions and emotional information. It has attracted great attention among researchers and Human Resource (HR) practitioners because of its input for leaders and employees and its key role in organizational effectiveness and excellence. Here, we describe the models of EI and review the findings to show the positive correlations between EI, leaders and employees. We conclude by indicating thoughts for future research on the role of EI in organizations.
\end{abstract}

Keywords - Human Resources, Emotional Intelligence, Organizations, Leadership, Employees, Team, Performance, Effectiveness.

\section{$1 \quad$ Introduction}

EI is described as the perception, evaluation, and management of emotions in yourself and others [1]. It is a concept that tries to connect both emotion and cognition and metacognitive processes [2-3].

Nowadays, working environments are more demanding and competitive due to a world economy which becomes more global with the mass influx of information and new technologies. The competition and demands that leaders and managers face today is intense and the excellence they need to succeed in their organizations hinges on learning and teamwork, as well as good intrapersonal and interpersonal relationships [4]. As a set of significant abilities, EI is attractive to HR specialists because it provides a framework of skills, which preexist, and are responsible for behaviors considered to help people be successful and effective at work [5]. Emotionally intelligent organizations can tap the talents of their workforce and tackle challenges more effectively. Managers and employees must be able to cooperate, to positively influence others and find faster and creative ways to accomplish tasks [6].

Research shows that emotions, properly managed, can lead to trust, faith and commitment. Productivity, innovations, success as individuals, groups or organizations 
Paper- Emotional Intelligence as an Important Asset for HR in Organizations: Leaders and Employees

can take place in such a context where EI plays a crucial role [7]. Reynolds and Vince (2004) comment on the centrality of emotion in the workplace: "Every organization is an emotional place because it is a human invention, serving human purposes and dependent on human beings to function... Emotion is what creates and sustains a system in its current form. Individuals and groups continually organize themselves both on the basis of their emotional responses to organizational issues, and on the basis of avoiding emotion" [8].

In a company or an organization leaders and employees should have emotional skills beyond technical ones. Leaders with EI can better understand their employees, create a friendlier and more accessible working environments, solve problems and make decisions based on having more self-management and self-control. It is highly probable that the performance of the company will grow under these conditions. Leader's with EI will be an inspiration, and will be able to transmit their thoughtfulness to their employees making them feel more efficient, happier and satisfied at work. Moreover, employees who have EI have better social awareness and social management skills, can be integrated into a group, and show greater performance results. Furthermore, they exhibit greater satisfaction, and the ability to manage stress.

This paper outlines the importance of EI to an organization by reviewing studies that have made the link between EI Leadership and Team Effectiveness. We point out how EI is associated with these two variables to better understand the role that EI can play in a working environment and we provide a framework for corporate effectiveness.

\section{The Models of Emotional Intelligence}

There are different approaches to model the concept of EI. These include the ability models, the mixed models (sometimes called emotional), social competence models, and the trait models [9].

The Mayer ability model is the most commonly accepted model of EI. Mayer and Salovey suggested that EI is a cognitive ability, which is separate but also associated with general intelligence. Specifically, Mayer, Salovey, Caruso, and Sitarenios [10] suggested that emotional intelligence consists of four skill dimensions: (1) perceiving emotion (i.e., the ability to detect emotions in faces, pictures, music, etc.); (2) facilitating thought with emotion (i.e., the ability to harness emotional information in one's thinking); (3) understanding emotions (i.e., the ability to understand emotional information); and (4) managing emotions (i.e., the ability to manage emotions for personal and interpersonal development). These skills are arranged hierarchically so that the perceptual emotion has a key role in facilitating thinking, understanding emotions, and managing emotions. These branches are arising from higher order basic skills, which evolve as a person matures. The psychometric tool they built to measure emotional intelligence refers to the objective measurement of abilities. The first test, constructed by Mayer, Salovey and Carouso, based on their theoretical model of emotional intelligence, is the MEIS test (1999). Afterwards, they published a more improved version, the MSCEIT test (2002) which is divided into four parts, the four branches described by their theory [11].

The Bar-On model belongs to mixed models. His approach is more psychological and refers to emotional intelligence as a series of interpersonal skills that affect an 
Paper- Emotional Intelligence as an Important Asset for HR in Organizations: Leaders and Employees

individual's behavior at various events in his life. According to Bar-On emotionalsocial intelligence is composed of emotional and social abilities, skills and facilitators. All these elements are interrelated and work together. They play a key role in how effectively we understand ourselves and others, how easily we express ourselves, but also in how we deal with daily demands. Bar-On's (2006) model of competencies and skills included: [...] the ability to be aware of, to understand, and to express oneself; the ability to be aware of, to understand and relate to others; the ability to deal with strong emotions and control one's impulses; and the ability to adapt to change and to solve problems of a personal or social nature. Bar-On's model, which he later named the BarOn model of ESI, includes the components of interpersonal skills, adaptability, stress management, and general mood [12]. To measure emotional intelligence, Bar-On, in 1992, produced one of the first self-reports on emotional intelligence, Bar-On EQ-i, which he then improved [13].

Daniel Goleman's mixed model (1998) defines Emotional Intelligence/Quotient as the ability to recognize our own feelings and those of others, to motivate ourselves, and to handle our emotions in order to have the best for ourselves and for our relationships. Emotional Intelligence describes capacities different from, but supplementary to, academic intelligence. Boyatzis and Goleman expanded the scope of their model to encompass social and emotional competencies linked to effective performance in the workplace and pointed out that it is composed of elements sorted into four "clusters" including self-awareness, self-management, social awareness, and relationship management [14]. To measure Emotional Intelligence, they constructed The Emotional Competence Inventory (ECI) test which consists of 72 items and it is both a self-report and multirater instrument [15].

Petrides and Furnham (2001) developed the Trait Emotional Intelligence model which is a combination of emotionally-related self-perceived abilities and moods that are found at the lowest levels of personality hierarchy and are evaluated through questionnaires and rating scales [16]. The trait EI essentially concerns our perceptions of our inner emotional world. An alternative tag for the same construct is trait emotional self-efficacy. People with high EI rankings believe that they are "in touch" with their feelings and can regulate them in a way that promotes prosperity. These people may enjoy higher levels of happiness. The trait EI feature sampling domain aims to provide complete coverage of emotional aspects of personality. Trait EI rejects the idea that emotions can be artificially objectified in order to be graded accurately along the IQ lines. The adult sampling domain of trait EI contains 15 facets: Adaptability, Assertiveness, Emotion perception (self and others), Emotion expression, Emotion management (others'), Emotion regulation, Impulsiveness (low), Relationships, Selfesteem, Self-motivation, Social awareness, Stress management, Trait empathy, Trait happiness, and Trait optimism [17].

\section{Empirical Studies: Reported Positive Results for Applying Emotional Intelligence in Leaders and Employees}

Studies and researches on emotional intelligence in the workplace have shown that emotional intelligence plays an important role in corporate development and 
Paper- Emotional Intelligence as an Important Asset for HR in Organizations: Leaders and Employees

performance at work, and that leadership with emotional intelligence is one of the main factors in creating a productive working environment that empowers workers and encourages them to make the most of their potential, which is directly related to the long-term business objective of most companies, which is to increase their profits and maximize return on their employees. The empirical studies in the literature review were conducted in a variety of industries and organizational settings and are quantitative.

\subsection{The Impact of Emotional Intelligence on Leadership Effectiveness}

According to Hogan et al. (1994) an aim of the leadership is to make people devote themselves to the common goals and obligations of an organization for the goal of the prosperity of the team and the organization as a whole [18]. Leadership is the process of communication (verbal and non-verbal) that involves coaching, motivating or inspiring, directing or guiding and supporting or counselling others [19]. Goleman et al. (2002) have supported that emotional intelligence is a crucial component of leadership effectiveness, even more when leaders are getting involved with teams [20]. Daniel Goleman (2003) identified five elements that a leader must have to be effective and successful: 1) self-awareness, 2) self-regulation, 3) motivation, 4) empathy, 5) social skill. Goleman (1998) pointed out that leaders with EI are better at managing relationships and succeed in effective performance by the power of emotions [21].

People (leaders) who manage emotionally - who know and control their feelings and distinguish and effectively treat the feelings of others - are beneficial in every area of life, whether they are emotional and familiar, or adhere to unwritten rules governing success in organizational policy.

In addition, empathy is considered a basic element in many leadership styles [22] which leads to high productivity and empowers corporate members in interacting cooperatively and reaching common goals through motivating, inspiring, understanding and recognizing needs, strengths, feelings, and thoughts [23].

Management based on emotional intelligence and empathy is built from neurological links [86]. Revolutionary discoveries in the field of brain research show that leaders' moods and actions have a decisive impact on those they direct, especially if leadership is operating with EI and empathic ability. Then, the leader has the capacity to inspire, to stimulate passion and enthusiasm, motivation and dedication, to support and understand employees and co-workers, and to give the confidence to constructively solve problems and conflicts that occur [24].

Ramchunder \& Martins (2014) used measurements in a total of 107 police personnel and confirmed a positive connection between emotional intelligence, self-efficacy and leadership effectiveness [25]. Batool (2013) explored the relationship between emotional intelligence and effective leadership at a managerial level in the private and public sector of Pakistan, mainly in the banking sector. Fifty people were questioned, and results indicated an important and positive correlation between leadership style and Emotional Intelligence [26]. Moreover, Gardner, \& Stough (2002) distributed a questionnaire to 250 high level managers. One-hundred and ten participants responded to the questionnaire and the findings supported the existence of a strong relationship between transformational leadership and overall EI [27]. 
Paper- Emotional Intelligence as an Important Asset for HR in Organizations: Leaders and Employees

Castro et al. (2012) examined the relationship among EI and employees' creativity. The survey took place in a hospital where data from two questionnaires were collected from leaders and from employees. The findings for these two variables were positive [28]. There are other numerous empirical studies that reflect this positive relationship between EI and leadership effectiveness for the best of employees and for the corporation [29-32].

\subsection{The Impact of Emotional Intelligence on Team Effectiveness}

Teams are a necessity in various organizations. People working as a team have a set of complementary skills, and are trying to succeed at the jobs, projects and goals that their organizations have set [33]. Effective Teams, aside from technical skills, must have emotional skills too. High EI teams are more creative, more cooperative, more effective, help each other, can differentiate their work in order to improve the outcomes of the team and the organization as a whole, can face difficulties or conflicts more constructively if they occur, think from different perspectives, and they can accept the diversity of people. Teams with high emotional intelligence skillfully manage and get the most from the personalities within the team, pay attention to both work and feelings, and regulate emotions in the team among the other members [34].

EI in a team helps build trust, respect and understanding among members which may lead to better participation and collaboration, which in turn will produce better decision making, productivity, creative solutions, and an overall flourishing working environment [35]. In a team everyone plays an important role in the overall level of emotional intelligence, and with the contribution of the manager greater EI results will be produced.

Appolus et al. (2016) research data has shown that emotional intelligence is inseparable from the workplace as it affects team effectiveness. Working in teams requires skills that help individuals to understand and regulate their emotions and those of others [36]. Aslan et al. (2008) also found that team emotional intelligence has a positive effect on team effectiveness. The study also revealed that the self-management dimension has the most influence on team effectiveness. Furthermore, a positive and significant correlation between the social awareness dimension and team effectiveness was found [37].

Jordan \& Lawrence (2009) in a recent study have highlighted that emotional Intelligence is linked to improved team behaviors and team performance [38]. Similar studies that have provided positive and important evidence regarding the relationship between EI and team performance and effectiveness are those of Elfenbein et al. 2006, Chang et al. 2012, Luca \& Tarricone, 2001 [39-41] etc.

Considering the positive effects of emotional intelligence in the areas mentioned above, it is concluded that when leaders and employees have emotional intelligence that can contribute to the efficiency and effectiveness of themselves, and as a whole team it can therefore contribute to the efficiency and effectiveness of the entire corporation (Figure 1). 


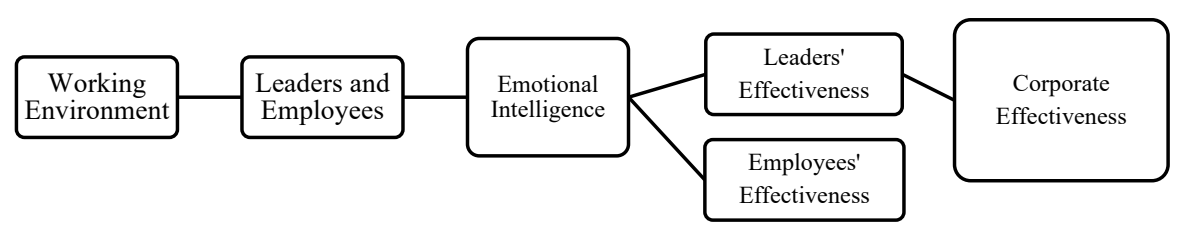

Fig. 1. A proposed framework of Emotional Intelligence in Organizations

\section{Discussion}

People are flooded with emotions every day, and feelings follow them in all the manifestations of their lives. Humans cannot be isolated from their feelings. Intelligence plays an important role, but emotional intelligence plays an equal one as far as behaviors and reactions are concerned. In the normal evolution of life, emotional intelligence tends to increase as we learn to be more aware of feelings, effectively handing distressing emotions, listening, and empathizing.

Research findings indicate the importance of EI both from the side of the leaders and from the side of the employees. Organizations must have a qualified workforce not only in technical abilities but in emotional ones. EI in the leadership of an organization directly affects the maintenance of high-quality employees, the overall productivity, encourages them, and creates a healthier working environment. Employees cooperate better as a team and have stronger and more effective interpersonal relationships, which is essential, taking into consideration that today many industries, organizations and corporations are multigenerational. Employees with emotional and empathic skills can express their emotions, understand themselves and their colleagues, deal with positive and negative emotions, difficult situations, and they can build a constructive environment where cooperation and collaboration exist and increase.

It is worth noting that Dewey used the concept of cooperative intelligence with the intention of pointing out the importance of cooperation and intelligence for a complete and ideal society within the framework of democracy [42]. Therefore, cooperative intelligence accompanied by emotional intelligence could be introduced within organizations since cooperation helps people interact and communicate better and create a friendlier and more effective environment.

Emotional intelligence, as the results of research show, can be one of the strong foundations of a company that will lead to a strong corporate governance [43]. Innovative approaches to corporate culture must be created and intervention training programs should be developed for the leaders, for the employees and for the workforce that is hired in a company to increase their EI levels. Furthermore, software, applications and virtual environments will be helpful for the purpose of acquiring EI skills, with the purpose of improving intrapersonal and interpersonal relationships, work performance and work success. Moreover, studies should be conducted in larger samples and in all kind of industries, organizations and businesses and in almost all 
Paper- Emotional Intelligence as an Important Asset for HR in Organizations: Leaders and Employees

countries in order to have an overall picture of the emotional intelligence in the working world. Consequently, integration programs related to EI will be designed more carefully and will be more targeted. It is important to mention that developing emotional and empathic skills is a long process with continuous effort, but in the end, everyone will benefit at the personal and group working level.

\section{References}

[1] Mayer, J.D.; Roberts, R.D.; Barsade, S.G. Human abilities: Emotional intelligence. Annu. Rev. Psychol. 2008, 59, 507-536. https://doi.org/10.1146/annurev.psych.59.103006.093646

[2] Gutiérrez-Cobo, M.J.; Cabello, R.; Fernández-Berrocal, P. The relationship between emotional intelligence and cool and hot cognitive processes: A systematic review. Front. Behav. Neurosci. 2016, 10, 101. https://doi.org/10.3389/fnbeh.2016.00101

[3] Drigas, A. S., \& Papoutsi, C. (2018). A New Layered Model on Emotional Intelligence. Behavioral Sciences, 8(5), 45. https://doi.org/10.3390/bs8050045

[4] Ulrich, D. (1998). A new mandate for human resources. Harvard business review, 76, 124135.

[5] Goleman, D., \& Cherniss, C. (2001). The emotionally intelligent workplace: How to select for, measure, and improve emotional intelligence in individuals, groups, and organizations. Jossey-Bass.

[6] Goleman, D., \& Cherniss, C. (2001). The emotionally intelligent workplace: How to select for, measure, and improve emotional intelligence in individuals, groups, and organizations. Jossey-Bass.

[7] Cooper, R.K. and Sawaf, A. (1997). Executive EQ: Emotional Intelligence in Leadership and Organizations, Grosset/Putnam, New York, NY. Dearborn.

[8] Reynolds, M. and Vince, R. (2004) 'Critical management education and action-based learning: Synergies and contradictions', Academy of Management, Learning and Education, 3(4), pp. 442-56. https://doi.org/10.5465/amle.2004.15112552

[9] McCleskey, J. (2014). Emotional intelligence and leadership: A review of the progress, controversy, and criticism. International Journal of Organizational Analysis, 22(1), 76-93. https://doi.org/10.1108/ijoa-03-2012-0568

[10] Mayer, J. D.; Salovey, P.; Caruso, D. R.; Sitarenios,G. Measuring emotional intelligence with the MSCEITV2.0. Emotion 2003, 3, 97-105. https://doi.org/10.1037/1528-3542.3.1.97

[11] Mayer, J. D. (2002), "MSCEIT: Mayer-Salovey-Caruso Emotional Intelligence Test", Toronto, Canada: Multi-Health Systems. https://doi.org/10.31274/rtd-180813-14322

[12] Bar-On, R. (2006). The Bar-On model of emotional-social intelligence (ESI) 1. Psicothema, 18(Suplemento), 13-25.

[13] Bar-On, R. [2004]. The Bar-On Emotional Quotient Inventory (EQ-i): Rationale, description, and summary of psychometric properties. In Glenn Geher (Ed.), Measuring emotional intelligence: Common ground and controversy. Hauppauge, NY: Nova Science Publishers, pp. 111-42.

[14] Boyatzis, R. (2009), "Competencies as a behavioral approach to emotional intelligence", The Journal of Management Development, Vol. 28 No. 9, pp. 749-770. https://doi.org/10.1108/02621710910987647

[15] Boyatzis, R. E., Goleman, D., \& Rhee, K. (2000). Clustering competence in emotional intelligence: Insights from the Emotional Competence Inventory (ECI). Handbook of emotional intelligence, 99(6), 343-362. 
Paper- Emotional Intelligence as an Important Asset for HR in Organizations: Leaders and

Employees

[16] Petrides, K.V.; Furnham, A. Trait emotional intelligence: Psychometric investigation with reference to established trait taxonomies. Eur. J. Personal. 2001, 15, 425-448. https://doi.org/10.1002/per.416

[17] Petrides, K.V. Trait emotional intelligence theory. Ind. Organ. Psychol. 2010, 3, 136-139. https://doi.org/10.1111/j.1754-9434.2010.01213.x

[18] Hogan, R., Curphy, G. J., \& Hogan, J. (1994). What we know about leadership: Effectiveness and personality. American psychologist, 49(6), 493. https://doi.org/10.1037//0003-066x.49.6.493

[19] Howard, W. C. (2005). Leadership: four styles. Education, 126(2), 384.

[20] Goleman, D., Boyatzis, R., \& McKee, A. (2002). Primal leadership: Realizing the power of emotional intelligence.

[21] Goleman, D. (2003). What makes a leader. Organizational influence processes, 229-241.

[22] Choi, J. (2006). A motivational theory of charismatic leadership: Envisioning, empathy, and empowerment. Journal of Leadership \& Organizational Studies, 13(1), 24-43. https://doi.org/10.1177/10717919070130010501

[23] Jin, Y. (2010). Emotional leadership as a key dimension of public relations leadership: A national survey of public relations leaders. Journal of Public Relations Research, 22(2), 159181. https://doi.org/10.1080/10627261003601622

[24] Badea, L., \& Pană, N. A. (2010). The Role of Empathy in Developing the Leader's Emotional Intelligence. Theoretical \& Applied Economics, 17(2).

[25] Ramchunder, Y., \& Martins, N. (2014). The role of self-efficacy, emotional intelligence and leadership style as attributes of leadership effectiveness. SA Journal of Industrial Psychology, 40(1), 01-11. https://doi.org/10.4102/sajip.v40i1.1100

[26] Batool, B. F. (2013). Emotional intelligence and effective leadership. Journal of Business Studies Quarterly, 4(3), 84.

[27] Gardner, L., \& Stough, C. (2002). Examining the relationship between leadership and emotional intelligence in senior level managers. Leadership \& organization development journal, 23(2), 68-78. https://doi.org/10.1108/01437730210419198

[28] Castro, F., Gomes, J., \& de Sousa, F. C. (2012). Do intelligent leaders make a difference? The effect of a leader's emotional intelligence on followers' creativity. Creativity and Innovation Management, 21(2), 171-182. https://doi.org/10.1111/j.14678691.2012.00636.x

[29] Altındağ, E., \& Kösedağı, Y. (2015). The relationship between emotional intelligence of managers, innovative corporate culture and employee performance. Procedia-Social and Behavioral Sciences, 210, 270-282. https://doi.org/10.1016/j.sbspro.2015.11.367

[30] Adeyemo, D. A., Terry, D. L., \& Lambert, N. J. (2015). Organizational climate, leadership style and emotional intelligence as predictors of quality of work life among bank workers in Ibadan, Nigeria. European Scientific Journal, ESJ, 11(4).

[31] Scott, B. A., Colquitt, J. A., Paddock, E. L., \& Judge, T. A. (2010). A daily investigation of the role of manager empathy on employee well-being. Organizational Behavior and Human Decision Processes, 113(2), 127-140. https://doi.org/10.1016/j.obhdp.2010.08.001

[32] Radhakrishnan, A., \& UdayaSuriyan, G. (2010). Emotional intelligence and its relationship with leadership practices. International Journal of Business and Management, 5(2), 65.

[33] Smit, P. J., Cronje, G. D., Brevis, T., \& Vrba, M. J. (Eds.). (2011). Management principles: A contemporary edition for Africa. Juta and Company Ltd.

[34] JCA Global, (2013). Team EI profile. [online] Available at: http://www.jcaglobal.com/whatwedo/products/team-emotional-intelligence/ [Accessed 22 Apr. 2015].

[35] Druskat, V. U., \& Wolff, S. B. (2001). Building the emotional intelligence of groups. Harvard business review, 79(3), 80-91. 
Paper- Emotional Intelligence as an Important Asset for HR in Organizations: Leaders and

Employees

[36] Appolus, O., Niemand, L., \& Karodia, A. M. (2016). An Evaluation of the Impact of Emotional Intelligence on Team Effectiveness among It Professionals at Bytes Systems Integration (South Africa). Kuwait Chapter of the Arabian Journal of Business and Management Review, 5(10), 79. https://doi.org/10.12816/0027368

[37] Aslan, S., Ozata, M., \& Mete, M. (2008). The investigation of effects of group emotional intelligence on team effectiveness. Humanity \& Social Sciences Journal, 3(2), 104-115.

[38] Jordan, P. J., \& Lawrence, S. A. (2009). Emotional intelligence in teams: Development and initial validation of the short version of the Workgroup Emotional Intelligence Profile (WEIP-S). Journal of Management \& Organization, 15(4), 452-469. https://doi.org/10.1017/s1833367200002546

[39] Elfenbein, H. A., Druskat, V. U., Sala, F., \& Mount, G. (2006). Team emotional intelligence: What it can mean and how it can affect performance. Linking emotional intelligence and performance at work: Current research evidence with individuals and groups, 165-184. https://doi.org/10.4324/9780203763896

[40] Chang, J. W., Sy, T., \& Choi, J. N. (2012). Team emotional intelligence and performance: Interactive dynamics between leaders and members. Small Group Research, 43(1), 75-104. https://doi.org/10.1177/1046496411415692

[41] Luca, J., \& Tarricone, P. (2001). Does emotional intelligence affect successful teamwork?.

[42] Campbell, J. (1995). Understanding John Dewey: nature and cooperative intelligence. Open Court Publishing.

[43] Trong Tuan, L. (2013). Emotional intelligence as the departure of the path to corporate governance. Corporate Governance: The international journal of business in society, 13(2), 148-168. https://doi.org/10.1108/14720701311316634

\section{Authors}

Athanasios Drigas is a Research Director at IIT-N.C.S.R. Demokritos. He is the Coordinator of Telecoms Lab and founder of Net Media Lab since 1996. From 1990 to 1999 he was the Operational manager of the Greek Academic network. He has been the Coordinator of Several International Projects, in the fields of ICTs, and eservices (elearning, e-psychology, e-government, e-inclusion, e-culture etc). He has published more than 300 articles, 7 books, 25 educational CD-ROMs and several patents. He has been a member of several International committees for the design and coordination of Network and ICT activities and of international conferences and journals. Also he has accepted several distinctions for his work (articles, projects, patents).

Chara Papoutsi is a PhD Candidate in Information and Communication Systems Engineering at the University of the Aegean in Samos, Greece. She holds a Master's degree in Applied Pedagogy at the National and Kapodistrian University of Athens. She is a teacher in a primary school. She has publications on empathy and emotional intelligence and she is also with NCSR DEMOKRITOS, Institute of Informatics and Telecommunications, Net Media Lab, Athens, Greece.

Article submitted 2018-10-04. Resubmitted 2018-12-17. Final acceptance 2019-02-14. Final version published as submitted by the authors. 